\title{
The Contribution of Ultrasound in Exploring Women Pelvic Pathologies in Two Teaching University Hospitals Maternities in Cotonou
}

\author{
Patricia Yekpe Ahouansou ${ }^{*}$, Sbmg Adjadohoun1, M. Saka1, G. N'Gamo1, T. E. Sansuamou², \\ Kofi-Mensa Savi De Tove ${ }^{3}$, Olivier Biaou', Vicentia Boco ${ }^{1}$ \\ ${ }^{1}$ National Teaching University Hospital Hubert Koutoukou Maga (CNHU-HKM), Medical Scanning Unit/University of \\ Abomey-Calavi, Cotonou, Benin \\ ${ }^{2}$ Radiology Department, Teaching University Hospital-Mother and Child Hospital, Cotonou, Benin (CHU-MEL) \\ ${ }^{3}$ Radiology and Medical Imaging Department, Departemental Teaching University Hospital Borgou, Parakou, Benin \\ Email: *Yfrida_pat@yahoo.fr
}

How to cite this paper: Ahouansou, P.Y., Adjadohoun, S., Saka, M., N'Gamo, G., Sansuamou, T.E., De Tove, K.-M.S., Biaou, O. and Boco, V. (2020) The Contribution of Ultrasound in Exploring Women Pelvic Pathologies in Two Teaching University Hospitals Maternities in Cotonou. Open Journal of Radiology, 10, 173-183. https://doi.org/10.4236/ojrad.2020.103017

Received: August 14, 2020

Accepted: September 22, 2020

Published: September 25, 2020

Copyright $\odot 2020$ by author(s) and Scientific Research Publishing Inc. This work is licensed under the Creative Commons Attribution International License (CC BY 4.0).

http://creativecommons.org/licenses/by/4.0/ (c) (i) Open Access

\begin{abstract}
Objective: The aim of this piece of work is to study the contribution of pelvic ultrasound while exploring pelvic pathologies at Hubert Koutoukou Maga Teaching University Hospital "CNHU-HKM" and at the Teaching University Hospital of Mother and Child "CHU-MEL" of Cotonou. Patients and Methods: A descriptive, cross-sectional and analytical study with prospective collection was carried out at the University Clinic of Gynecology and Obstetrics "CUGO" at the CNHU-HKM and in the gynecology department of the CHU-MEL, over a period of 4 months (May to August 2018). We included in this study women over 12 years old who performed a pelvic ultrasound and were followed in the aforementioned health centers. Results: The population of the study consisted of 181 patients. The pelvic ultrasound request frequency was $18.84 \%$ compared to all ultrasound examinations. The age group of 25 - 29 years old was the most represented (22.10\%). Pelvic pain was the first motive for pelvic ultrasound request (39.8\%). The abnormalities found by ultrasound were uterine and ovarian respectively in $55.4 \%$ and $38 \%$ of cases. Uterine pathology was dominated by uterine myoma (44\%). Ovarian cyst (13\%) and ovarian dystrophy (14\%) were the main ovarian pathologies. There was a statistically significant relationship between certain reasons for consultation, mainly metrorrhagia, dysmenorrhoea, amenorrhoea, leucorrhoea ( $\mathrm{p}<$ $5 \%$ ) and the ultrasound result. Conclusion: The ultrasound remains the first choice examination and is of a great value in exploring pelvic pathologies. In most cases, it helps to find the responsible lesion and to make the appropriate therapeutic decisions.
\end{abstract}




\section{Keywords}

Ultrasound, Pelvis, Woman, Cotonou

\section{Introduction}

Ultrasound is the preferred modality for exploring female reproductive system. It is the first choice examination considered as an extension of gynecological examination [1]. Introduced in the medical field in the 1960s, ultrasound has since found applications in almost all medical specialties [2]. It has the advantage of being reliable, repetitive, non-invasive, and available in our workplace. According to Fethia et al. [3], the pelvic ultrasound performed by the endovaginal route is an innocuous and readily available means of investigation to explore the uterus and appendices.

It is the first choice examination in the vast majority of uterine and/or annex pelvic pathologies, "PIVOT" of pelvic exploration [4] [5].

In Benin, ultrasounds are performed in the management of multiple pathologies that have been subject to several publications. However, very few studies have been carried out on the pelvic condition. This is the reason for this study which aims at studying the contribution of ultrasound in exploring pelvic conditions in women.

\section{Patients and Methods}

It was a descriptive, cross-sectional, analytical and multicentric study with prospective collection, over a period of 04 months from May 1st 2018 to August 31st 2018. It took place at the University Clinic of Gynecology and Obstetrics "CUGO" of the Teaching University Hospital of Hubert Koutoukou Maga "CNHU-HKM" and in the gynecology department of the Teaching University Hospital of Mother and Child "CHU-MEL".

We involved in this study women over 12 years old who performed a pelvic ultrasound for a pelvic pathology and were followed in the aforementioned hospitals. Those with an intra- or ectopic pregnancy discovered during the ultrasound as well as those with incomplete clinical record were excluded.

The Ultrasound scans were performed using two (02) ultrasound scanners: a HITACHI EUB-5500 2D ultrasound scanner with color Doppler and 03 probes: an abdominal $(2-5 \mathrm{mHz})$, an endovaginal $(7.5 \mathrm{mHz})$ and a linear $(7.5 \mathrm{mHz})$ and a 2D ultrasound scanner MINDRAY DP-8500 without colour Doppler and equipped with 02 probes: an abdominal $(3.5 \mathrm{mHz})$ and endovaginal $(6.5 \mathrm{mHz})$.

The variables studied included age, medical, surgical and gynecological history, reason for admission, ultrasound data mainly the reasons for ultrasound requests and the pathologies found. All the women directed to the ultrasound unit of these hospitals, who present a confirmed or suspected pelvic pathology after the clinical examinations carried out by gynecologists, have been comprehen- 
sively counted. The ultrasound was performed by the suprapubic or endovaginal route either by the radiologist or the gynecologist. The information was collected using a previously prepared survey sheet.

The statistical analysis was done in SPSS 25 and EPI DATA 3.1 software. The Pearson Chi-square test was used to analyze the relationship between the qualitative variables. Quantitative variables were expressed on average with their standard deviation and confidence interval at $95 \%$. The significance threshold chosen was $\mathrm{p}<0.05$.

From ethical point of view, we received the authorization of the heads of CUGO department, CNHU-HKM and of CHU-MEL, and the informed consent from the patients. The confidentiality of the data was guaranteed.

\section{Results}

Hospital Frequency of Pelvic Ultrasounds (Figure 1).

During the period of study, 2032 ultrasounds were performed in the ultrasound units of the CNHU and CHU MEL, of which 383 pelvic ultrasounds; accounting for $18.84 \%$ of the ultrasound activity. Out of the three hundred and eighty-three (383) pelvic ultrasounds performed, only 181 patients were included in the study (47.25\%). And of the 181 patients selected, 95 (52.5\%) ultrasounds were performed at the CNHU-HKM and 86 (47.5\%) at the CHU-MEL.

\subsection{Epidemiological and Clinical Profile of Patients}

The average age was $35.15 \pm 10.39$ with extremes of 13 and 67 years old. The most represented age group was 25 - 29 years old.

Patient histories are listed in Table 1.

The menstrual cycle was regular in 57 cases accounting for $31.50 \%$ and irregular in 111 cases representing $61.30 \%$. Among the patients with regular menstrual cycle the average duration of the cycle was $28.38 \pm 1.50$ days with extremes of 23 and 30 days.

There was as much appendicectomy as myomectomy (2.8\%).

Abortion was noted in 77 patients accounting for $42.5 \%$, aged on average $37.19 \pm 10.3$ years old. MIUA was noted in 50 patients accounting for $27.6 \%$, aged on average $37.18 \pm 10.36$ years old the various reasons for requesting pelvic ultrasound are shown in Table 2.

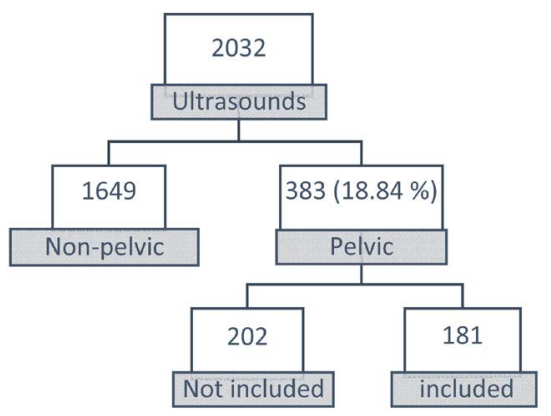

Figure 1. Flow chart of ultrasound scans performed. 
Table 1. Distribution of patients by history.

\begin{tabular}{ccc}
\hline & N & $\%$ \\
\hline Menstrual cycle or period & 57 & 31.50 \\
Regular & 111 & 61.30 \\
Irregular & 13 & 7.20 \\
Unspecified & & \\
Surgical history & 5 & 2.8 \\
Appendectomy & 5 & 2.8 \\
Myomectomy & 3 & 1.6 \\
Laparotomy & 77 & 42.5 \\
Abortion & 50 & 27.6 \\
MIUA* & 35 & 19.3 \\
Cesarean & &
\end{tabular}

${ }^{*}$ MIUA: Manual Intrauterine Aspiration.

Table 2. Patient distribution by ultrasound indications.

\begin{tabular}{ccc}
\hline & N & $\%$ \\
\hline Pelvic pain & 72 & 39.8 \\
Menometrorrhagia & 35 & 19.33 \\
Dysmeorrhea & 24 & 13.25 \\
Amenorrhea & 24 & 13.25 \\
Pelvic mass & 9 & 4.97 \\
Tumor extension & 7 & 3.87 \\
Spaniomenorrhea & 6 & 3.31 \\
IUD Position & 4 & 2.21 \\
Total & 181 & 100 \\
\hline
\end{tabular}

It appears that pelvic algia was the most common $(39.80 \%)$ in most of our patients, followed by menorrhagia (19.33\%).

\subsection{Distribution of Ultrasound Lesions}

Route of ultrasounds performed (Figure 2).

Among the 181 ultrasound examinations performed, the endovaginal route was used exclusively in $52.50 \%$ of our patients, and the suprapubic in $26 \%$.

The ultrasound was pathological in 124 patients, accounting for $68.50 \%$ (Table 3).

The lesions detected by ultrasound were dominated by uterine pathology which represented $55.4 \%$, with myomas leading in $44 \%$ followed by ovarian pathology in $38 \%$.

There was a polymyomatous uterus in $62.3 \%$ of cases. In $46.8 \%$ of myoma 
$\mathrm{N}=181$

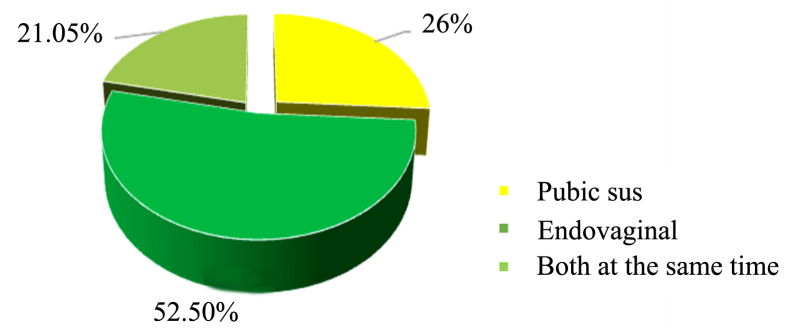

Figure 2. Distribution according to the route used to perform the ultrasound.

Table 3. Distribution of ultrasound lesions.

\begin{tabular}{ccc}
\hline & N & $\%$ \\
\hline Uterinespathology & 97 & 55.4 \\
Uterinemyomas & 77 & 44 \\
Endométrial hypertrophy & 7 & 4 \\
Endométriale hypotrophy & 6 & 3.4 \\
Hematometry & 3 & 1.7 \\
Adenomyosis & 1 & 0.6 \\
Myomatousnecrobiosis & 1 & 0.6 \\
Uterinesynechia & 1 & 0.6 \\
Uterine Hypoplasia & 1 & 06 \\
ovarian Pathologies & 67 & 38 \\
Ovarian Dystrophy* & 25 & 14 \\
ovarian Cyst & 23 & 13 \\
ovarian Hypotrophy & 19 & 11 \\
Tubal Pathologies & 1 & 0.6 \\
Pyosalpinx & 1 & 06 \\
Other lesions & 11 & 6 \\
Fluid effusion in Douglas & 9 & 5 \\
Uncomplicated bladder lithiasis & 2 & 100 \\
Total & 176 & 5 \\
\hline
\end{tabular}

*Organic 7 (30.5\%) Functional 16 (69.5\%); ${ }^{*}$ Macrocyst 2 (8\%) Microcyst 23 (92\%).

cases, interstitial and sub-serous localization occurred in $18.2 \%$ of cases. In patients with multiple myomas, there was an association of myomas (sub-serous, sub-mucous and interstitial) in $5.2 \%$ of cases.

\subsection{Correlation Ship between Reason for Consultation and Ultrasound Results (Table 4)}

There was a statistically significant relationship in cases of dysmenorrhea, metrorrhagia, amenorrhea and leucorrhea.

It appears that patients who consult for metrorrhagia had a pathological ultrasound result in $90.24 \%$ of cases and $9.75 \%$ had a normal result. 
Table 4. Analysis between reason for consultation and ultrasound results.

\begin{tabular}{|c|c|c|c|c|c|}
\hline & \multicolumn{2}{|c|}{ ultrasound results } & \multirow{2}{*}{ OR } & \multirow{2}{*}{ IC $(95 \%)$} & \multirow{2}{*}{ p-value } \\
\hline & Pathology & Normal & & & \\
\hline \multicolumn{6}{|l|}{ Motive of consultation } \\
\hline Pelvic pain & & & & & 1.000 \\
\hline yes & $49(68.1 \%)$ & $23(3.9 \%)$ & 0.96 & $0.3-1.6$ & \\
\hline No & $75(68.8 \%)$ & $34(31.2 \%)$ & 1 & & \\
\hline Dysmenorrhea & & & & & 0.014 \\
\hline Yes & $29(54.7 \%)$ & $24(45.3 \%)$ & 0.41 & $-0.2-1.1$ & \\
\hline No & $95(74.2 \%)$ & $33(25.8 \%)$ & 1 & & \\
\hline Metrorrhagia & & & & & 0.002 \\
\hline Yes & $37(90.24 \%)$ & $4(9.75 \%)$ & 5.63 & $4.5-6.7$ & \\
\hline No & $87(62.1 \%)$ & $53(37.9 \%)$ & 1 & & \\
\hline Menorrhagia & & & & & 0.556 \\
\hline Yes & $28(73.7 \%)$ & $10(26.3 \%)$ & 1.37 & $0.5-2.1$ & \\
\hline No & $96(67.1 \%)$ & $47(32.9 \%)$ & 1 & & \\
\hline Spaniomenorrhea & & & & & 0.683 \\
\hline yes & $23(71.9 \%)$ & $9(28.1 \%)$ & 1.21 & $0.37-2.05$ & \\
\hline No & $101(67.8 \%)$ & $48(32.2 \%)$ & 1 & & \\
\hline Amenorrhea & & & & & 0.009 \\
\hline Yes & $27(90.0 \%)$ & $3(10.0 \%)$ & 5.01 & $3.7-6.2$ & \\
\hline No & $97(64.2 \%)$ & $54(35.8 \%)$ & 1 & & \\
\hline Desire for motherhood & & & & & 1.000 \\
\hline Yes & $19(67.9 \%)$ & $9(32.1 \%)$ & 0.96 & $0.1-1.8$ & \\
\hline No & $105(68.6 \%)$ & $48(31.4 \%)$ & 1 & & \\
\hline premenstrual Syndrome & & & & & 0.446 \\
\hline Yes & $12(60.0 \%)$ & $8(40.0 \%)$ & 0.65 & $-0.2-1.6$ & \\
\hline No & $112(69.6 \%)$ & $49(30.4 \%)$ & 1 & & \\
\hline Leucorrhea & & & & & 0.002 \\
\hline Yes & $3(25 \%)$ & $9(75 \%)$ & 0.13 & $-1.2-1.4$ & \\
\hline No & $121(71.6 \%)$ & $48(28.4 \%)$ & 1 & & \\
\hline \multicolumn{6}{|l|}{ Oligomenorrhea } \\
\hline Yes & $4(50 \%)$ & $4(50 \%)$ & 0.44 & $-0.9-1.8$ & 0.438 \\
\hline No & $120(69.4 \%)$ & $53(30.6 \%)$ & 1 & & \\
\hline
\end{tabular}

\section{Discussion}

\subsection{Hospital Frequency of Pelvic Ultrasounds}

Pelvic ultrasound in this study accounted for $18.84 \%$ of all ultrasound activities. Koussema [4], in Togo, in his study of pelvic pain noted $4.50 \%$ rate of pelvic ul- 
trasound out of all ultrasound scans. This difference is understandable for his work dealt only with pelvic pain. However, this relatively low rate, compared to what we got, could be explained by the limited access of women to pelvic ultrasound due to financial constrain.

\subsection{Epidemiological and Clinical Profile of Patients}

\section{Age}

The average age was 35.15 years old with extremes of 13 and 67 years old. We noticed an increase in pelvic ultrasound performance in the age group of 25 - 29 years old with a frequency of $22.10 \%$. Koussema [4] found that the age of the patients ranged from 10 to 65 years old with an average age of 37 years and 6 months old, close to our results. For AkoAhui [1], patients between 25 and 35 years old were the most numerous; this age group can be superimposed on that of our study.

These results can easily be explained since pelvic conditions most often concern patients in periods of genital activity.

\section{Reasons for pelvic ultrasound request}

In this study, pelvic pain was the main motive for pelvic ultrasound (39.8\%), just as was in NGbessoand al's [5] in Ivory coast, who observed that pelvic pains were a frequent reason for consultation with $36.94 \%$ of rate. According to Genevois [6] et al., they accounted for 5\% of gynaecological consultations. According to HAHN et al., pelvic pain has a prevalence of $15 \%$ in a female population aged from 18 to 50 years old [7]. Acute pelvic pain, isolated or associated with metrorrhagia or fever, is very common but non-specific core symptoms of patients who consult in emergency department by Balleyguier et al. [8].

\subsection{Pelvic Ultrasound Data}

\section{Route used}

The endovaginal route was the most used accounting for $52.50 \%$ and the suprapubic was $26 \%$. Our results are different from those of Boco et al. [9] whose most patients had undergone suprapubic examination in $95.1 \%$. Likewise in Koussema's [4] whose patients were examined only by the suprapubic route.

According to Ardeans et al. [10] the two routes are complementary; we must choose the best one for a given structure. The suprapubic scan retains all its indications and, except in special cases, still remains the first-line of the common exam. But the use of a vaginal probe brings major advantages: unnecessary bladder repair, better definition by the proximity and high frequency of the probes, no discomfort due to parietal adiposity. Its disadvantages include the reduction of the exploration field.

In this study, $31.50 \%$ of the ultrasounds were normal versus $68.50 \%$ pathological. Unlike Koussema [4] et al., who found in their study $48 \%$ of pathological examinations versus $52 \%$ normal. This difference could be linked to the population of study, which only consisted of pelvic pain in the Togolese studies. Boco [9] in Benin found a rate, significantly lower than ours in 9.9\% in 2003. The in- 
crease in the number of specialists and the ultrasound scanners since then could explain this difference.

Our results are similar to those of Ako Ahui et al., who reported 25.5\% normal versus $74.5 \%$ of pathological ultrasound [1].

The abnormalities found by ultrasound were uterine (55.4\%), ovarian (38\%) and to a lesser level tubal (0.6\%).

Koussema et al. [4] and Ako Ahui [1] drew up more or less the same etiological catalogue on ultrasound, but in different proportions respectively $32.7 \%$ and $28.2 \%$ for uterine disease, $36.3 \%$ and $64.1 \%$ for ovarian disease, and $1.8 \%$ and $7.7 \%$ for tubal disease.

Uterine disease was dominated by myomas (79.3\%) (Figure 3). This finding is widely reported in the literature [11]. N'gbesso [5] claimed that fibroids accounted for $92 \%$ of utero-vaginal masses, and Kouamé et al. [12] 52.2\% of uterine conditions. Myoma is a common condition affecting $20 \%-30 \%$ of women during genital activity [13] [14]. Uterine myomas remain the prerogative of the young black woman [5] [13] [14]. These same authors evoke a genetic factor linked to the susceptibility of the black patient to develop more readily fibrous tissue abnormalities [5] [14]. Polymyomatous uterus was $62.3 \%$, a frequency close to that of Koussema [4] of $52.27 \%$. One might say that it is rare for uterine myoma to be unique.

Endometrial hypertrophies found especially by the endovaginal route accounted for $7.21 \%$ of uterine affections. The ultrasound especially endovaginal is of a capital contribution in this pathology because clinically, the metrorrhagia can refer to other gynecological pathologies mainly the myomatous. Hanchi et al. [15] asserted that endovaginal pelvic ultrasound in an elderly woman may alert in front of an endometrial thickening; though the hysteroscopy with directed biopsies is the diagnosis method of choice.

Ovarian pathologies ranked second in our study with $38 \%$ of cases.

Cystic dystrophies in $37.31 \%$ dominated by microcystic form (92\%) (Figure 4 ), and ovarian cysts in $34.33 \%$ dominated by functional cysts (69.5\%), represented the most common ovarian abnormalities. Koussema, N'gbésso, and Kouamé [4] [5] [12] have also made the same observation in different proportions, with a predominance of functional cysts. These authors agree with the literature that asserts that these are the most common ovary lesions in women during genital activity, representing at least $2 / 3$ of the ovarian cysts. Ultrasound is of a major contribution because it is more sensitive than the clinic as pointed out by Marret et al. [16], who assessed the sensitivity of ultrasound in ovarian masses at $80 \%$ on average.

Ultrasound helps to have a fairly perfect analysis of the organs forming the upper genital sphere of a woman. It should be the first choice examination in exploring female pelvis [4]. It specifies the site and nature of a possible causal lesion with the advantage of an extended exploration to the rest of the pelvic cavity or even the abdomen. 


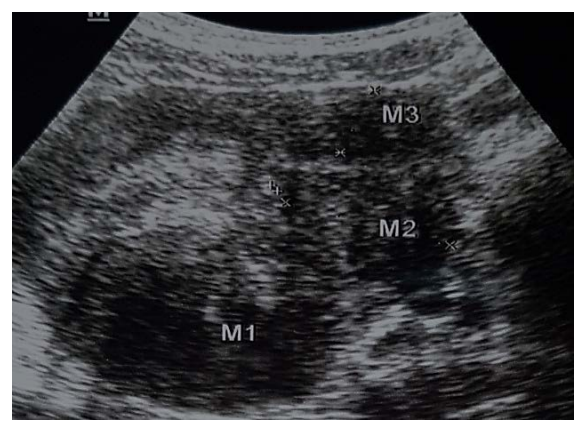

Figure 3. Transverse suprapubic ultrasound section: Polymyomatous uterus (Radiology department CNHU-HKM).

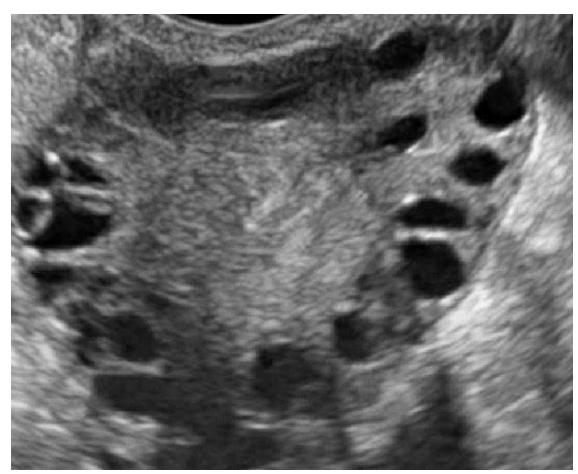

Figure 4. Ovarian dystrophy microcystic (CNHU-HKM).

\subsection{Correlation Ship between Reason for Consultation and Ultrasound Results}

$90.24 \%$ of patients with metrorrhagia had a pathological ultrasound scan versus $37.9 \%$ with a normal result. There was a statistically significant relationship ( $\mathrm{p}=$ 0.002 ) between the presence of metrorrhagia and the ultrasound result. Furthermore, patients with metrorrhagia were about five times more likely to have a pathological ultrasound than one without this sign $(\mathrm{OR}=5.63 ; 95 \% \mathrm{CI}=4.5$ 6.7).

A statistically significant relationship was also found between the ultrasound result and three other reasons for consultation, namely dysmenorrhea, amenorrhea and leucorrhoea, respectively with a p-value of $0.014 ; 0.009$ and 0.002 .

This leads us to conclude that ultrasound scan plays an important role in the etiological investigation of amenorrhea, metrorrhagia, dysmenorrhea and leucorrhoea. This observation is corroborated by other authors such as Sétchéou et al. [17]; Fethia et al. [3] and Bidet [18], respectively for amenorrhea, metrorrhagia and dysmenorrhea.

\section{Conclusion}

The hospital frequency of pelvic ultrasound scan was relatively low at CUGO (CNHU-HKM) and (CHUMEL). Pelvic pain was the most frequent cause. Uterine pathologies were the most common, dominated by myomas. There was a statistically significant relationship between the presence of metrorrhagia, dys- 
menorrhoea, amenorrhoea and leucorrhoea $(\mathrm{p}<5 \%)$ and the ultrasound result. Thus, ultrasound remains the first choice in exploring pelvic pathologies in women. It should therefore be desirable to improve accessibility to all women in the genital activity.

\section{Limitations of the Study}

The unavailability of complete ultrasound report logs in the units of those hospitals.

The reluctance of some patients to join the survey.

The large number of patients excluded because some of them were not followed in the gynaecological units that were our study framework.

Failure to perform ultrasound after prescription due to financial cost.

\section{Authors' Contributions}

Patricia YEKPE conceived the study. SBMG ADJADOHOUN and M. SAKA collected the data. Patricia YEKPE and SBMG ADJADOHOUN analyzed and drafted the manuscript. All authors approved the final version of the article.

\section{Conflicts of Interest}

The authors declare that there is no conflict of interest.

\section{References}

[1] Ako-Ahui, E., N’guessan, K.E., Konan, A.N., Sétchéou, A., Ettien, J.J.K., Kouamé, N., et al. (2019) Diagnostic étiologique échographique des douleurs pelviennes aigues de la femme en Côte d'Ivoire. European Scientific Journal, 15, 437-447. https://doi.org/10.19044/esj

[2] Poitier, A., Opinel, M., D’Ercole, C. and Blanc, B. (1994) Echographie en gynécologie. In: Encycl. Méd. Chir, Gynécologie, Editions Techniques, Paris, 69-A-10, 23 p.

[3] Fethia, B., AmelAchour, J., Sarah, S., Anissa, G., Eya, G., Ezzeddine, S., et al. (2016) L'apport de l'échographie dans l'exploration des métrorragies post-menopausiques. Pan African Medical Journal, 24, 175. https://doi.org/10.11604/pamj.2016.24.175.7361

[4] Koussema, A.L.K., Hondegla, A.A.B., Anoukoum, T., Folligan, K., Davi, D. and Awobanou, K. (2011) Echographie sus pubienne dans les douleurs pelviennes chez la femme à Lomé. Journal Africain d' imagerie Médicale, 6, 300-307.

[5] N'Gbesso, R.D., N'Goan, A.M., Coulibaly, A., Mushi, M., Diabaté, K. and Keita, A.K. (1996) Apport de l'échographie: Masses utéro-vaginales et pelviennes chez la femme noire africaine. Cahiers de santé, 6, 145-150.

[6] Genevois, A., Marouteau, N., Lemercier, E., Dacher, J.N. and Thiebot, J. (2008) Imagerie de la douleur pelvienne aiguë. Journal de Radiologie, 89, 92-105. https://doi.org/10.1016/S0221-0363(08)70379-2

[7] Hahn, L. (2001) Chronic Pelvic Pain in Women. A Condition Difficult to Diagnose More than Different Diagnoses Can Be Considered. Lakartidningen, 98, 1780-1785.

[8] Balleyguier, C., Bazot, M., Eiss, D., Salem, C. and Hélénon, O. (2004) Diagnostic radiologique d'une algie pelvienne de la femme. Feuillets de Radiologie, 44, 5-13. 
https://doi.org/10.1016/S0181-9801(04)94720-3

[9] Boco, V., Takpara, I. and Adisso, S. (2003) Intérêt de l'échographie dans le diagnostic étiologique des douleurs pelviennes chez la femme en période d'activité génitale. Journal Africain d imagerie Médicale, 1, 73-82.

[10] Ardaens, Y., Guérin, B., Coquel, P., Levaillant, J.M. and Poncelet, E. (2010) Echographie et imagerie pelvienne en pratique gynécologique. Collection Imagerie médicale Précis. $5^{\text {ème }}$ édition, Masson, Paris, $643 \mathrm{p}$.

[11] Gallix, B., Maubon, A., Rouanet, J.P. and Borel, P. (1993) Echographie de l'utérus. In: Jouve, P., Ed., Manuel d’ ultrasonologie de Padulte, Masson, Paris, 231-244.

[12] Kouamé, N., N'goan-Domoua, A., Konan, N., et al. (2012) Apport de l'échographie transvaginale associée à l'hystérosalpingographie dans la recherche étiologique de l'infertilité féminine à Abidjan (Côte d'Ivoire). African Journal of Reproductive Health, 16, 43.

[13] Laghzaoui, M., Bouhya, S. and Hermas, S. (2001) Epidémiologie des fibromes utérins. Maroc médical A, 23, 266-270.

[14] Chalal, N. and Demmouche, A. (2013) Profil épidémiologique des fibromes utérins dans la région de Sidi Bel Abbes Algérie. Pan African Med Journal, 15, 7. https://doi.org/10.11604/pamj.2013.15.7.2690

[15] Hanchi, Z., Berrada, R. and Fadli, A. (2003) Les hypertrophies de l'endomètre. Maroc Médical A, 25, 41-45.

[16] Marret, H., Cosson, M. and Goffinet, F. (2001) Echographie et doppler dans le diagnostic des kystes ovariens: Indications, pertinence des critères diagnostiques. Journal de Gynécologie obstétrique et biologie de reproduction A, 30, 20-33.

[17] Sétchéou, A., Kouamé, N., Touré, A., Garba, I., Konan, N.A., Tra bi, Z.O., et al. (2015) Apport de l'imagerie dans la recherche étiologique des aménorrhées primaires. Journal Africain Imagerie Médicale, 1, 64-72.

[18] Bidet, M. (2013) Dysménorrhée de l'adolescente. Mt Médecine de la Reproduction, Gynécologie Endocrinologie, 15, 328-333. 